\title{
Visual Search for Feature and Conjunction Targets with an Attention Deficit
}

\section{Citation}

Arguin, Martin, Yves Joanette, and Patrick Cavanagh. 1993. Visual search for feature and conjunction targets with an attention deficit. Journal of Cognitive Neuroscience 5(4): 436-452.

\section{Published Version}

doi:10.1162/jocn.1993.5.4.436

\section{Permanent link}

http://nrs.harvard.edu/urn-3:HUL.InstRepos:3626283

\section{Terms of Use}

This article was downloaded from Harvard University's DASH repository, and is made available under the terms and conditions applicable to Other Posted Material, as set forth at http:// nrs.harvard.edu/urn-3:HUL.InstRepos:dash.current.terms-of-use\#LAA

\section{Share Your Story}

The Harvard community has made this article openly available.

Please share how this access benefits you. Submit a story.

Accessibility 


\title{
Visual Search for Feature and Conjunction Targets with an Attention Deficit
}

\author{
Martin Arguin \\ Montreal Neurological Institute \\ Yves Joanette \\ Université de Montréal \\ Patrick Cavanagh \\ Harvard University
}

\begin{abstract}
Brain-damaged subjects who had previously been identified as suffering from a visual attention deficit for contralesional stimulation were tested on a series of visual search tasks. The experiments examined the hypothesis that the processing of single features is preattentive but that feature integration, necessary for the correct perception of conjunctions of features, requires attention (Treisman \& Gelade, 1980; Treisman \& Sato, 1990). Subjects searched for a feature target (orientation or color) or for a conjunction target (orientation and color) in unilateral displays in which the number of items presented was variable. Ocular fixation was controlled so that trials on which
\end{abstract}

\section{INTRODUCTION}

One of the most influential proposals in vision research during the last decade is Treisman's feature integration theory of attention (Treisman, 1988; Treisman \& Gelade, 1980; Treisman \& Sato, 1990; Treisman \& Schmidt, 1982; Treisman \& Souther, 1985). According to this model, the encoding of visual features (e.g., orientation or color) is performed through analyses that are preattentive and accomplished in a spatially parallel fashion across the visual field. Conversely, one task that is assumed to require attentional processing is the integration of visual features, which is a necessary condition for correctly perceiving feature conjunctions (e.g., colored shapes).

To now, most of the evidence for these two hypotheses comes from studies performed on normal, neurologically intact individuals. In the present paper, our main purpose is to examine more directly the role of attention in visual feature integration by studying the performance of left brain-damaged subjects in visual search tasks where the target is distinguished from the distractors by a single feature or by a conjunction of features. In particular, we are interested in the performance of a

eye movements occurred were cancelled. While brain-damaged subjects with a visual attention disorder (VAD subjects) performed similarly to normal controls in feature search tasks, they showed a marked deficit in conjunction search. Specifcally, VAD subjects exhibited an important reduction of their serial search rates for a conjunction target with contralesional displays. In support of Treisman's feature integration theory, a visual attention deficit leads to a marked impairment in feature integration whereas it does not appear to affect feature encoding.

subgroup of left brain-damaged subjects who have been shown, in a previous series of experiments (Arguin, Cavanagh, \& Joanette, 1992), to suffer from a disorder affecting the allocation of attention to stimuli presented in their contralesional visual hemifield.

\section{VISUAL FEATURES AND THEIR INTEGRATION}

Objects in our visual environment differ from one another on a number of perceptual dimensions. Empirical demonstrations have indicated, in the human as well as the animal, that the visual system comprises a number of functional modules, each specialized for the processing of visual features on a specific perceptual dimension (see, among others, Allman, Baker, Newsome, \& Peterson, 1981; Cavanagh, 1988; De Yoe \& Van Essen, 1988; Kaas, 1989; Zeki, 1978). However, the identification of visual objects not only requires that features along each of these dimensions be specified, but also demands an explicit representation of how they are combined to constitute each individual object (Treisman \& Gelade, 
1980; Treisman \& Sato, 1990; Treisman \& Schmidt, 1982; Treisman, Sykes, \& Gelade, 1977).

At present, it appears that the most viable hypothesis regarding the process responsible for conjoining features is that it is performed by focusing visuospatial attention at the location occupied by the stimulus (Keele, Cohen, Ivry, Liotti, \& Yee, 1988; Treisman \& Sato, 1990). Treisman and her collaborators have proposed a theory of visual feature integration that applies this principle (Treisman, 1982, 1983, 1985, 1988, 1991; Treisman \& Gelade, 1980; Treisman \& Paterson, 1984; Treisman \& Schmidt, 1982; Treisman \& Sato, 1990; Treisman \& Souther, 1985; Treisman et al., 1977). This theory proposes two distinct stages in visual processing. The first, called preattentive, allows the spatially parallel encoding of features that are present in the visual field. At the preattentive stage, information regarding the location of specific features is not made explicitly available. The second stage, called attentive, is responsible for the integration of features that have been encoded at the preattentive stage by focusing visuospatial attention at the location occupied by a particular stimulus. Without attention, the features that are encoded cannot be located properly-they are said to be free-floating-and may thus lead to the perception of illusory conjunctions (i.e., the erroneous integration of features that do not belong to the same object; Briand \& Klein, 1987; Eglin, 1987; Prinzmetal, 1981; Prinzmetal, Presti, \& Posner, 1986; Treisman \& Paterson, 1984; Treisman \& Schmidt, 1982; Treisman et al., 1977; Virzi \& Egeth, 1984).

Empirical support for Treisman's feature integration theory has been reported with the use of various experimental paradigms in neurologically intact subjects (see Treisman \& Sato, 1990, for a review). One main source of evidence relative to the function of visuospatial attention in feature integration comes from the visual search paradigm. In the present paper, we will concentrate on this particular paradigm.

In the visual search task, subjects are asked to indicate, as rapidly as possible while avoiding errors, whether a prespecified stimulus, called target, is present in an array of other stimuli, called distractors, whose number is variable. When the target differs from distractors by a unique feature (e.g., red target, green distractors) a large number of experiments show that the time required by normal individuals to detect the presence of a target is independent of the number of stimuli that are presented (Arguin \& Cavanagh, 1988; Bergen \& Julesz, 1983; Cavanagh, Arguin, \& Treisman, 1990; Dick, Ullman, \& Sagi, 1987; Nakayama \& Silverman, 1986; Quinlan \& Humphreys, 1987; Sagi \& Julesz, 1985; Treisman, 1982, 1983, 1985, 1988; Treisman \& Gelade, 1980; Treisman \& Gormican, 1988; Treisman \& Souther, 1985; Treisman et al., 1977). Thus, the slope of the linear regression of response times (RTs) as a function of the number of items is about $0 \mathrm{msec} / \mathrm{item}$. These observations indicate that detection of a feature target is performed by a spatially parallel process that does not involve the selection of individual stimuli by visuospatial attention (Snodgrass $\&$ Townsend, 1980), and thus support the hypothesis of a preattentive encoding of visual features. More specifically, this preattentive process is said to involve the monitoring of signals coming from a sensory map responsible for the encoding of the target's distinctive feature.

In contrast to feature targets, conjunction targets can be distinguished from distractors only by considering the combinations of features constituting the items presented (Treisman \& Gelade, 1980). For example, if the target is a red horizontal bar, one subgroup of distractors is made of red vertical bars and another of green horizontal bars. With such displays, the target cannot be distinguished from distractors by a unique feature since it shares its color with some distractors and its orientation with others. In most of the experiments requiring normal subjects to search for a conjunction target, results show linearly increasing RTs with the number of stimuli displayed (Arguin \& Cavanagh, 1988; 1990; Arguin, Joanette, \& Cavanagh, 1990; Dehaene, 1989; Egeth, Virzi, \& Garbart, 1984; Houck \& Hoffman, 1986; Pashler, 1987; Quinlan \& Humphreys, 1987; Treisman, 1982, 1983, 1985, 1988; Treisman \& Gelade, 1980; Treisman \& Sato, 1990; Treisman et al., 1977; Wolfe, Cave, \& Franzel, 1989). This is taken as an indication that search is performed through the sequential examination of each item in turn (Snodgrass \& Townsend, 1980). It thus appears that focusing visuospatial attention at the location occupied by a particular stimulus is necessary to correctly perceive the conjunction of its features, in support of Treisman's feature integration theory.

However, there exists another set of observations that poses a challenge to Treisman's feature integration theory. Indeed, experiments led by Nakayama and Silverman (1986), Steinman (1987), Mcleod, Driver, and Crisp (1988), Sagi (1988), Wolfe et al. (1989), Dehaene (1989), Treisman and Sato (1990), and Arguin and Cavanagh (1990) show that visual search for some types of conjunction targets can be performed correctly with a very shallow increase in RTs as a function of the number of items displayed, suggesting a process that is spatially parallel instead of serial. On this basis, a number of authors have proposed that attention may not be required to integrate some feature combinations (Mcleod et al., 1988; Nakayama \& Silverman, 1986; Sagi, 1988), contrary to the basic hypothesis of Treisman's feature integration theory.

\section{BRAIN DAMAGE AND VISUAL SEARCH FOR FEATURE AND CONUUNCTION TARGETS}

Riddoch and Humphreys (1987) and Eglin, Robertson, and Knight (1989) examined the visual search performance of brain-damaged subjects who have been diagnosed as showing visual hemineglect, which is a 
syndrome generally thought to reflect, at least in part, a deficit of visual attention for contralesional stimulation (Heilman, 1985; Kinsbourne, 1970; Mesulam, 1981; Morrow \& Ratcliff, 1988; Roy, Reuter-Lorenz, Roy, Copland, \& Moscovitch, 1987). Specifically, Riddoch and Humphreys (1987) and Eglin et al. (1989) have compared the effect of the number of items displayed on RTs as a function of the side (ipsilesional vs. contralesional) of the display to which the target was presented. Performance was examined in search tasks involving either feature or conjunction targets. Riddoch and Humphreys (1987) tested subjects only with bilateral displays while Eglin et al. (1989) used both unilateral and bilateral displays. None of these studies performed any control for the locus of eye fixation at the onset of trials or checked for the occurrence of eye movements during the search process. In fact, many of the subjects tested by Riddoch and Humphreys (1987; two out of three patients) and by Eglin et al. (1989; four out of seven patients) suffered from either a verified or probable visual field defect. Therefore, it is quite possible that a number of neglect subjects in those experiments searched the displays by examining them through their ipsilesional hemifield. These are not ideal conditions to test the performance of the damaged hemisphere on visual search tasks and this may explain some of their findings, as indicated below.

The results reported by Riddoch and Humphreys (1987) suggest that neglect subjects performed a spatially parallel search for a feature target, whatever side to which the target was presented. In contrast, Eglin et al. (1989) reported results suggesting that neglect subjects performed the search for a feature target through a serial process irrespective of the side of the display on which the target appeared. This result differs from that observed in normal individuals who, as indicated earlier, typically search for a feature target through a spatially parallel process. Both the studies reported by Riddoch and Humphreys (1987) and by Eglin et al. (1989) showed main effects indicating longer RTs for a contralesional target than for an ipsilesional one. It is possible that this last result may be partly attributable to the eye movements that neglect subjects with a visual field deficit had to perform in order to view the target in their ipsilesional hemifield. An examination of the individual data reported by Riddoch and Humphreys (1987) and by Eglin et al. (1989) nevertheless suggests that this is not the only factor involved in the RT asymmetry observed in neglect subjects since it was apparent even in patients without any visual field defect. ${ }^{1}$

With a conjunction target, the results reported in these two studies indicate a regular increase of RTs with the number of items displayed, thus suggesting a serial search that involved focused attention. Again, RTs were longer with contralesional targets. However, no significant difference in the effect of the number of items on RTs as a function of the side to which the target was presented is reported, even though Riddoch and Humphreys (1987) underlined a clear trend for a slower serial search with contralesional targets. As mentioned previously, no control of ocular fixation was performed in these experiments and this may have been a factor in the lack of significant hemifield differences in the rate of conjunction search.

In the present paper, we report a series of three visual search experiments that were designed as a test of two of Treisman's basic hypotheses about the encoding of visual features and feature conjunctions, namely that single feature encoding can be performed in a spatially parallel manner without the aid of focused attention, and that the correct perception of feature conjunctions requires that attention be focused at the stimulus location. Strict eye movement monitoring and brief exposure durations were used to ensure control over the lateralization of the stimuli presented.

The tasks used required subjects to search for a feature target differing from distractors either by its orientation (horizontal vs. vertical; Exp. 1) or its color (red vs. green; Exp, 2), or to search for a conjunction target that differed from distractors by a specific combination of orientation and color (Exp. 3). The features used in the latter experiment were the same as those used in Exps. 1 and 2. Stimulus displays were made of one, two, three, or four items and were shown unilaterally for a brief duration. Ocular fixation was controlled in order to make sure of the proper lateralization of stimulation.

The experimental group was made up of left braindamaged $^{2}$ subjects who had previously shown evidence for an attention deficit for contralesional stimulation in a separate set of visuospatial cuing experiments (VAD group-for visual attention deficit; Arguin et al., 1993). The attention deficit of the VAD group was revealed by longer RTs to contralesional than ipsilesional targets at short stimulus onset asynchronies ( 50 and $150 \mathrm{msec}$ ) following a spatial cue that indicated, on $80 \%$ of the trials, the hemifield in which the target would occur (invalid cues were presented on the remaining $20 \%$ of trials). The occurrence of this hemifield asymmetry was not directly related to the validity of the spatial cue (i.e., whether it indicated the target location or not) and was even seen in a task where no cue validity effect occurred (see the subject description in the Method section for a full description). The RT asymmetry between ipsilesional and contralesional targets was much reduced or absent at longer stimulus onset asynchronies (600 and 1000 $\mathrm{msec}$ ) between cues and targets. This pattern of results suggested that VAD subjects had a deficit in maintaining a proper level of alertness for contralesional stimulation. Of the control groups used in the present set of visual search experiments, one was made of left brain-damaged subjects who did not show any evidence for an attention disorder (i.e., normal performance) in visuospatial cuing tasks (nVAD group). The other control group was made up of neurologically intact subjects whose age approxi- 
mately matched that of the brain-damaged subjects (normal controls). None of the brain-damaged subjects showed any visual field impairment.

The aspect of main interest in the visual search results reported below were differences between hemifields in the effect of the number of items presented on RTs. Following Treisman's feature integration theory, an attention deficit should not affect performance in the search for a feature target since this task is assumed to be executed by preattentive processes. In contrast, since it is assumed that search for a conjunction target requires attentional processing, it was expected that subjects suffering from a visual attention deficit (VAD group) would show impaired performance with right-hemifield (contralesional) displays relative to control subjects. Specifically, if attention is required for visual feature integration, subjects with an attention deficit should take longer to process each individual item located in the part of space to which they have difficulty to attend, thus leading to a larger increase of RTs with the number of stimuli presented.

\section{RESULTS AND DISCUSSION}

\section{Experiment 1-Orientation Search}

Figure 1 shows the correct RTs observed in each group when the feature target differed from distractors displayed with it by its orientation. Table 1 depicts the error rates observed in this task. The correlation between RTs and error rates was null $(r=0.00)$, thus indicating the absence of a speed-accuracy trade-off.

To briefly summarize the analyses described below, the results of Exp. 1 did not reveal any significant linear increase of RTs as a function of the number of stimuli presented in any condition or for any of the subject groups. Rather, on target-absent trials, all groups showed evidence for longer RTs if only a single item was shown than if two, three, or four were exposed. For the VAD group, data analyses also suggested a comparable effect of the number of stimuli on target-present trials. No evidence for an effect of the number of items on targetpresent trials was observed in the control and nVAD groups.

\section{Results}

A mixed-factor ANOVA was performed on the median correct RTs observed in each subject. Within-subject factors were the visual hemifield to which the stimuli were displayed (hemifield), the target's presence or absence (target), and the number of items presented (number). The between-subject factor was made from the three groups (control, nVAD, and VAD). Similar analyses were also performed on the data of Exps. 2 and 3.

The analysis of variance applied on the correct RTs showed significant two-way interactions of group $\times$ num-

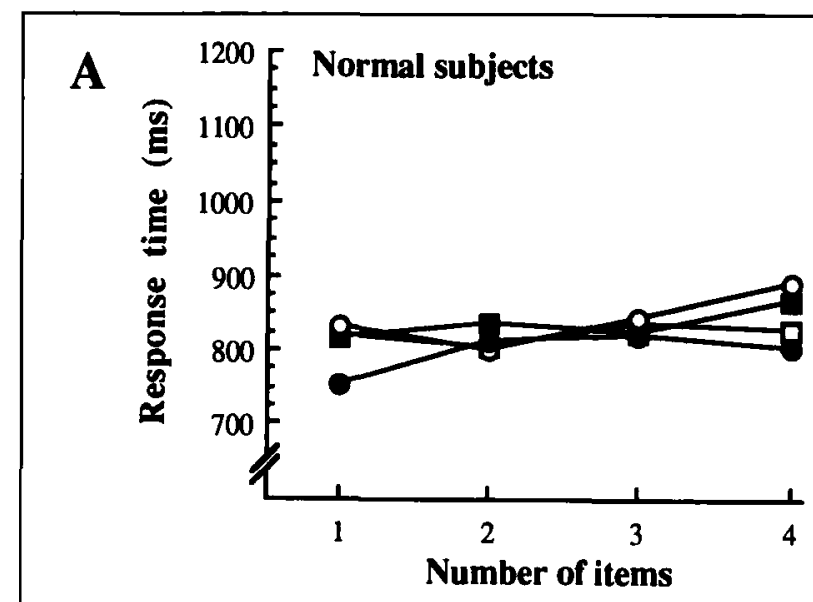

B

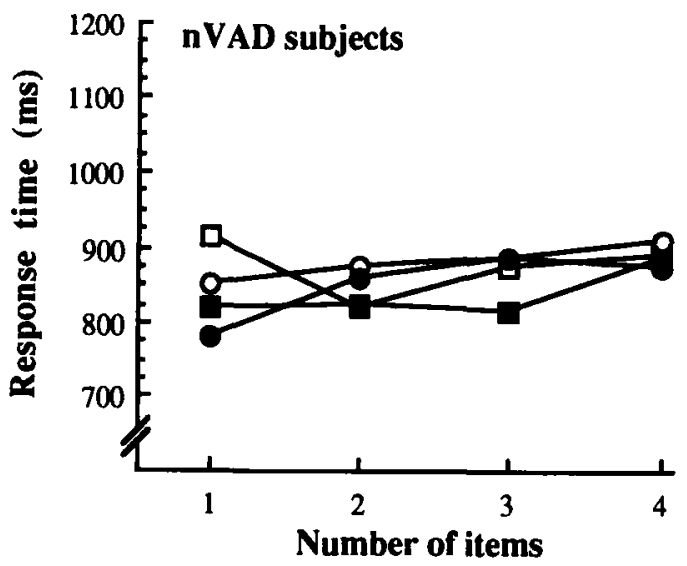

C

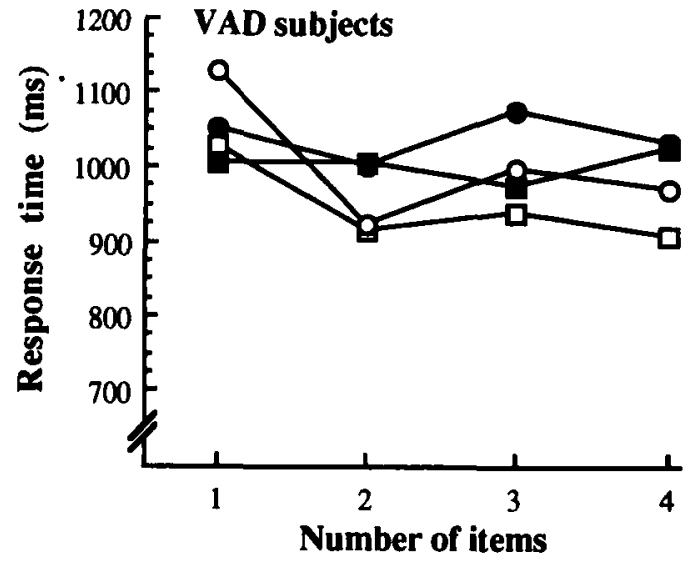

Figure 1. Mean RTs observed in Exp. 1 (orientation search). (A) Control group. (B) nVAD group. (C) VAD group. Square, left hemifield display; circle, right-hemifield display; filled symbols, targetpresent trials; empty symbols, target-absent trials.

ber of items $[F(6,45)=2.5, p<0.05]$, and of target $\times$ number $[F(3,45)=4.2, p<0.025]$. No other effect was significant.

Analysis of the simple effects of the group $\times$ number interaction showed that the effect of the number of items 
Table 1. Percentages of Errors Observed in the Orientation Search Experiment (Experiment 1) ${ }^{a}$

\begin{tabular}{cccccc}
\hline $\begin{array}{c}\text { Number of } \\
\text { Items }\end{array}$ & Group & $L-A$ & $L-P$ & $R-A$ & $R-P$ \\
\hline & Control & & & & \\
1 & & 1.3 & 5.3 & 1.3 & 2.0 \\
2 & & 0.7 & 2.7 & 1.3 & 2.0 \\
3 & & 3.3 & 1.3 & 7.3 & 1.3 \\
4 & & 6.6 & 1.3 & 10.6 & 1.3 \\
& nVAD & & & & \\
1 & & 6.7 & 5.3 & 12.0 & 12.0 \\
2 & & 2.7 & 8.0 & 8.0 & 12.0 \\
3 & & 5.3 & 2.7 & 8.0 & 4.0 \\
4 & & 5.3 & 9.3 & 12.0 & 8.0 \\
& VAD & & & & \\
1 & & 8.9 & 8.9 & 0.0 & 0.0 \\
2 & & 2.2 & 2.2 & 4.4 & 4.5 \\
3 & & 4.4 & 4.4 & 4.5 & 4.4 \\
4 & & 0.0 & 4.4 & 6.7 & 4.4 \\
\hline
\end{tabular}

${ }^{a} \mathrm{~L}$, Left hemifield; $\mathbf{R}$, right hemifield; $A$, target-absent trials; $P$, targetpresent trials.

was significant only in the VAD group $\{[F(3,45)=2.8$, n.s.] for the normal controls, $[F(3,45)=2.0$, n.s. $]$ for the nVAD group, $[F(3,45)=3.5, p<0.025]$ for the VAD group\}. A linear regression applied on the pooled results of the VAD group indicated a nonlinear decrease of RTs with the number of items presented (slope $=-17.6$ msec/item, $r=0.58$ ). This effect mainly consisted in longer RTs when only one stimulus was presented than when two, three, or four were displayed.

Analysis of the simple effects of the target $\times$ number interaction indicated that the effect of number of items was significant only on target-absent trials $\{[F(3,45)=$ 2.7, n.s. $]$ for target-present, $[F(3,45)=3.5, p<0.025]$ for target-absent\}. A linear regression applied on the pooled results on target-absent trials showed that the variation of RTs as a function of the number of items was nonlinear $(r=0.28)$ and was most apparent in that RTs were longer if only one stimulus was displayed than when two, three, or four items were presented.

\section{Discussion}

The main aspect of the results of Exp. 1 is that there was no significant increase of RTs with the number of stimuli presented in any condition or group. This is consistent with the existing literature indicating the spatially parallel search for feature targets. In fact, RTs often decreased as the number of items in the display increased. Thus, for all groups but only on target-absent trials, RTs were longer if only one item was presented than if two or more were in the display. An indication for a comparable effect of the number of items on target-present trials was observed in the VAD group. This latter effect was quite weak however, and only emerged because of shorter RTs with displays made of two stimuli. Thus, RTs of the VAD group on target-present trials were of 1028, 1002, 1024, and $1027 \mathrm{msec}$ for display sizes of $1,2,3$, and 4, respectively. Performance differences between target-present and target-absent trials have been reported on several occasions in the literature on feature search (e.g., Cavanagh et al., 1990; Farmer \& Taylor, 1980; Quinlan \& Humphreys, 1987; Treisman, 1982, 1991; Treisman \& Gelade, 1980). These differences indicate that even though feature encoding proceeds through a spatially parallel process in both kinds of trials, the particular criteria on which the decisions as to the presence or the absence of the target may vary (see Treisman, 1991; Treisman \& Gelade, 1980; Treisman \& Gormican, 1988).

The effect of the number of items on RTs that occurred on target-absent trials suggests that subjects used a strategy in which target-absent responses were based on the homogeneity of the stimulus display. On this account, when two or more stimuli were shown on a target-absent trial, the homogeneity of the display (all distractors were vertical) was used by subjects as a signal that the target (i.e., a contrasting stimulus-horizontal bar) was absent. Obviously, when only one item was shown on targetabsent trials, this homogeneity detection strategy could not apply. In that case, subjects may have had to rely on some explicit identification of the stimulus or on a comparison between it and an internal target template, thus leading to longer RTs. Two points should be mentioned about this homogeneity detection strategy on targetabsent trials.

First, the application of such a process is apparently not uncommon, as it has previously been observed in several experiments with normal subjects (Duncan \& Humphreys, 1989; Estes, 1972; Farmer \& Taylor, 1980; Gordon, 1968; Gordon, Dulewicz, \& Winwood, 1971; McIntyre, Fox, \& Neale, 1970; Moraglia, Maloney, Fekete, \& Al-Basi, 1989; Treisman, 1991; Treisman \& Sato, 1990; Wolfe, Friedman-Hill, Stewart, \& O'Connell, 1992). One example of this was reported by Farmer and Taylor (1980). In an experiment where subjects had to search for an achromatic target among chromatic distractors, these authors manipulated the level of homogeneity of the distractors. They showed that RTs to target-absent trials were greatly reduced by the use of homogeneous distractors, as opposed to a heterogeneous set.

Second, the application of the strategy of homogeneity detection indicates the capacity of subjects in encoding orientation through a spatially parallel process. Indeed, the successful application of a homogeneity detection process implies the parallel processing of orientation stimuli. That is, no benefit from display homogeneity 
would have occurred in the present experiment if search had been based on the sequential processing of the stimuli.

The converse of homogeneity detection, which is the detection of heterogeneity (i.e., a discrepant item), did not occur on target-present trials in Exp. 1. This type of search process would predict longer RTs with displays of one item than with displays made of two or more stimuli. In contrast, the target-present results indicated no significant variation of RTs with the number of items. Such observations are consistent with the view that the presence of a feature target (here a horizontal bar) is detected on the basis of activity within the sensory map involved in the encoding of the distinctive feature of the target (e.g., Treisman, 1991; Treisman \& Gormican, 1988).

The main purpose of Exp. 1 was to examine whether, as in neurologically intact individuals, the orientation of visual lines can be encoded by a spatially parallel process in subjects who suffer from an attention deficit (VAD group). Since the orientation search performance of the VAD subjects was nearly identical to that of the control and nVAD groups, the results of Exp. 1 support the hy. pothesis that an attention deficit does not prevent the spatially parallel processing of orientation.

\section{Experiment 2-Color Search}

Figure 2 shows the RTs observed in each group when the target differed from distractors by its color. Table 2 depicts the error rates observed in this task. The correlation between RTs and error rates was positive $(r=$ +0.22 ), thus indicating the absence of a speed-accuracy trade-off.

In summary, the results of Exp. 2 indicated that the number of items did not affect RTs with left-hemifield exposures. With right-hemifield displays however, the number of stimuli shown affected performance, although differently on target-absent and target-present trials. Thus, with target-absent right-hemifield presentations, RTs were longer when only one item was shown than when two, three, or four were present. With right-hemifield displays in which the target was present, normal controls as well as VAD subjects showed a significant linear increase of RTs with the number of items presented. The effect of the number of stimuli did not differ between these two groups.

\section{Results}

The analysis of variance applied on the correct RTs in Exp. 2 revealed a significant two-way interaction of target $X$ number of items $[F(3,45)=9.1, p<0.001]$, a threeway interaction of hemifield $\times$ target $\times$ number $[F(3$, $45)=4.1, p<0.025]$, and a four-way interaction of hemifield $\times$ target $\times$ group $\times$ number $[F(6,45)=3.3$, $p<0.01]$. No other significant effect was found. Since

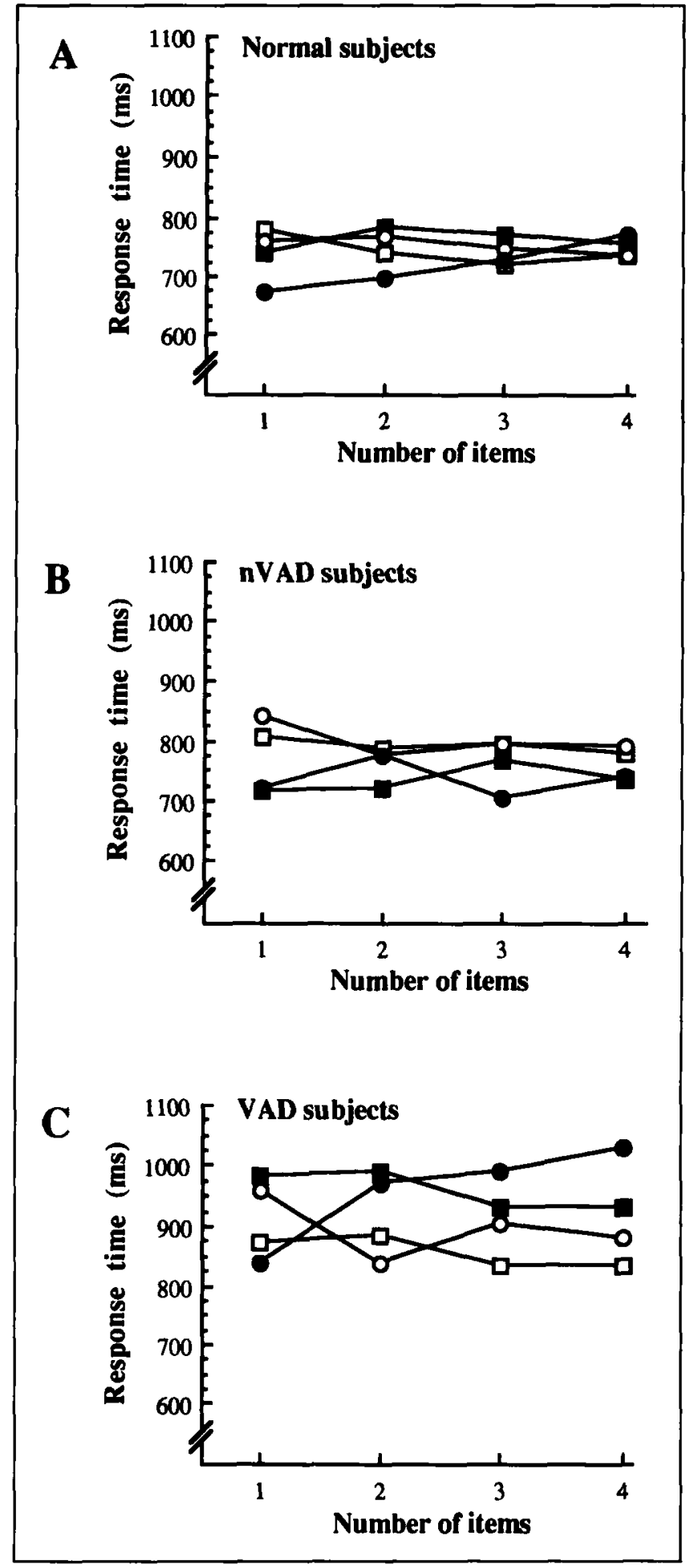

Figure 2. Mean RTs observed in Exp. 2 (color search). (A) Control group. (B) nVAD group. (C) VAD group. Square, left hemifield display; circle, right-hemifield display; filled symbols, target-present trials; empty symbols, target-absent trials. Note that the scale of the vertical axis differs from that used in Figure 1.

the four-way interaction included all the factors examined, only the simple effects related to this interaction were analyzed.

For left-hemifield displays, analysis of the hemifield $x$ 
Table 2. Percentages of Errors Observed in the Color Search Experiment (Experiment 2$)^{a}$

\begin{tabular}{cccccc}
\hline $\begin{array}{c}\text { Number of } \\
\text { Items }\end{array}$ & Group & $L-A$ & $L-P$ & $R-A$ & $R-P$ \\
\hline & Control & & & & \\
1 & & 0.7 & 2.0 & 0.7 & 0.0 \\
2 & & 1.3 & 1.3 & 2.0 & 2.0 \\
3 & & 0.0 & 4.7 & 2.0 & 2.7 \\
4 & & 2.0 & 6.0 & 2.7 & 2.7 \\
& nVAD & & & & \\
1 & & 2.7 & 2.6 & 2.7 & 1.3 \\
2 & & 4.0 & 2.7 & 6.7 & 0.0 \\
3 & & 0.0 & 5.3 & 6.6 & 4.0 \\
4 & & 1.3 & 6.6 & 9.3 & 4.0 \\
& VAD & & & & \\
1 & & 0.0 & 1.3 & 2.2 & 0.0 \\
2 & & 4.4 & 2.2 & 6.7 & 0.0 \\
3 & & 0.0 & 1.1 & 2.2 & 2.2 \\
4 & & 2.2 & 8.9 & 6.6 & 0.0 \\
\hline
\end{tabular}

${ }^{a}$ Conventions are the same as in Table 1.

target $\times$ group $\times$ number interaction showed no significant effect. In contrast, a similar analysis performed on the data observed with right-hemifield stimulation showed a target $\times$ number interaction $[F(3,45)=13.8$, $p<0.001]$ as well as a target $\times$ group $\times$ number interaction $[F(6,45)=3.8, p<0.005]$.

An examination of the group and number effects on target-absent right-hemifield trials indicated a significant effect only of the number of items $[F(3,45)=5.2, p<$ 0.005 ]. A linear regression of the data observed on these trials, pooled across groups, showed a reduction of RTs with increasing number of stimuli (slope $=-12.7 \mathrm{msec}$ item, $r=0.63$ ). This effect was mainly manifest by the longer RTs observed when only one item was presented relative to displays with two, three, or four stimuli. With target-present right-hemifield displays, the analysis showed an effect of number of items $[F(3,45)=6.9$, $p<0.005$ ] and a marginally significant interaction of group $\times$ number of items $[F(6,45)=2.2, p<0.06]$. Decomposition of this interaction revealed a significant effect of number of items in both the normal controls $[F(3,45)=4.7, p<0.025]$ and the $\operatorname{VAD}$ group $[F(3,45)$ $=5.2, p<0.01]$. In contrast, no effect of the number of stimuli $[F(3,45)=1.3$, n.s. $]$ was observed in the nVAD group on target-present right-hemifield trials. Linear regressions on the target-present right-hemifield data for the control and VAD groups showed linear increases of RTs with the number of stimuli in both groups (controls: slope $=32.8 \mathrm{msec} / \mathrm{item}, r=0.99 ; \mathrm{VAD}:$ slope $=58.6$ msec/item, $r=0.92$ ). A separate ANOVA was run in order to directly compare these effects of the number of items in the control and VAD group. It indicated that the magnitude with which RTs increased with additional items on target-present trials with right-hemifield stimulation did not differ between the two groups [interaction of group $\times$ number: $F(3,33)=1.4$, n.s.]

\section{Discussion}

The results seen in Exp. 2 with left-hemifield displays are congruent with the hypothesis of a spatially parallel search for a color target. Thus no group showed any effect of the number of items on RTs with left-hemifield stimulation. This result corresponds to what is generally reported in the literature on color search in a normal population and suggests that with left-hemifield displays, the task was performed through the monitoring of signals from a feature map responsible for encoding the target. The observations with right-hemifield stimulations are more complex however. Thus, even though there is evidence in all groups that color could be encoded by a spatially parallel process with right-hemifield displays, the actual operations by which target-present and targetabsent decisions were reached were markedly different.

On right-hemifield target-absent trials, all groups showed longer RTs to displays containing only one item than to displays of two, three, or four stimuli. This result suggests a homogeneity detection strategy similar to that observed on target-absent trials in Exp. 1. Thus, with displays within which stimulus homogeneity could be detected (set sizes of two, three, or four), RTs were reduced relative to a condition in which no such signal was present (set size of one). As mentioned in the discussion of Exp. 1, this type of effect suggests that the color of the stimuli could be encoded by a spatially parallel process. Hence, had colors been treated through a serial process in this condition, no benefit from display homogeneity would have been observed.

In sharp contrast, however, normal controls and VAD subjects, but not nVAD subjects, showed significant linear increases of RTs with increasing number of items on right-hemifield target-present trials. This suggests that before responding that the target was present, subjects performed a sequential examination of individual items. Serial search for a color target has been observed before, but only in cases where the colors used for the distractors were very similar to that of the target (Treisman, 1991; Treisman \& Gormican, 1988). Here, the target and distractors were highly discriminable (red vs. green) and such contrasting stimuli normally give flat RT functions with varying numbers of items. Finally, our results on right-hemifield target-present trials do not appear attributable to the use of equiluminant colors in Exp. 2 (see Method section). Previous visual search observations by Cavanagh et al. (1990) and by D'Zmura (1991) with equi- 
luminant colors indicated no effect of the number of items on RT's.

What appears as the most reasonable account of the results of Exp. 2 with target-present trials is based on the hypothesis of a hemispheric difference in color processing. Bryden (1982) and Davidoff (1982) have previously described a qualitative difference between the two hemispheres in color processing. In their reviews, they noted a right-hemisphere superiority in color discrimination, whereas the left hemisphere appears superior for color labeling. It is possible that the superior color discrimination skills of the right hemisphere might support a parallel process for target-present responses whereas the superior color labeling of the left hemisphere might not. This may explain the unexpected hemifield asymmetry observed on target-present trials in the control and VAD groups. This finding, should it hold up in future tests, implies that there are qualitative differences in processing strategies between the hemispheres in the visual search for color targets. The reason for the discrepant results in the nVAD group however, whose data suggest they did not revert to a serial search process on righthemifield target-present trials, remains unclear. It is possible that particular aspects of the brain damage seen in nVAD subjects are related to their divergent performance. To the best of our knowledge, no other experiment has yet studied the color search performances of the right and left cerebral hemispheres with a careful control of stimulus lateralization. The results of Exp. 2 suggest that this may be an interesting research direction for the study of cerebral asymmetries in color processing.

The main question we attempted to answer in Exp. 2 was whether an attention deficit prevents the spatially parallel encoding of color. As already pointed out, an anomaly with respect to the literature on color search in neurologically intact individuals was observed in the VAD group. Thus, VAD subjects appeared to have searched for the target through the monitoring of the feature map responsible for encoding the target with left-hemifield displays. In contrast, the results with right-hemifield stimulation suggest that the VAD subjects monitored a signal as to the homogeneity of the display and, in the absence of this signal, performed an examination of individual items through focused attention. Obviously, this anomaly complicates the interpretation of the results. However, it should be noted that a similar pattern of results was also observed in the normal controls. In addition, the magnitude of the effect of the number of items on RTs with right-hemifield target-present displays did not differ significantly between the normal controls and the VAD group. Furthermore, and more importantly, the capacity of the VAD group to successfully apply a homogeneity detection strategy on right-hemifield target-absent trials (i.e., significant benefits from display homogeneity) suggests that these patients are capable to encode color through a spatially parallel process in spite of their attention deficit.

\section{Experiment 3-Conjunction Search}

Figure 3 shows the RTs observed in each group when subjects searched for a target differing from distractors by a conjunction of orientation and color. Table 3 presents the error rates observed in this task. The correlation between RTs and error rates was positive $(r=+0.39)$, thus indicating the absence of a speed-accuracy tradeoff.

The results of Exp. 3 indicated linear increases of RTs as a function of the number of items displayed and this effect did not vary as a function of target presence or absence. With left-hemifield stimulation, the only significant effect observed was one of the number of stimuli. Thus, RTs increased linearly with the number of items presented and this effect did not vary significantly as a function of group. In contrast, with right-hemifield displays, VAD subjects exhibited a larger increase of RTs with the number of stimuli than the control group. The nVAD group showed a performance that was comparable with that of the normal controls. Details of the data analyses are presented below.

\section{Results}

The analysis of variance applied on the correct RTs revealed significant main effects of hemifield $[F(1,15)=$ $28.5, p<0.001]$ and of number of items $[F(3,45)=42.5$, $p<0.001]$, two-way interactions of hemifield $\times$ group $[F(2,15)=20.8, p<0.001]$, of group $\times$ number $[F(6$, $45)=2.6, p<0.05]$, and of hemifield $\times$ number $[F(3$, 45) $=7.6, p<0.001]$, and a three-way interaction of hemifield $\times$ group $\times$ number $[F(6,45)=3.2, p<0.025]$. No other significant effect was found. Only the three-way interaction was analyzed any further since it included all the factors involved in the other significant effects.

For left-hemifield stimulation, simple effects analysis of the hemifield $\times$ group $\times$ number interaction only showed a main effect of the number of stimuli $[F(3,45)$ $=23.11, p<0.001]$. The linear regression of RTs as a function of the number of stimuli for left-hemifield displays, which was applied on the results pooled across groups and target-absent and target-present trials, indicated a fairly large linear increase of RTs with the number of items (slope $=58.1 \mathrm{msec} / \mathrm{item}, r=0.96$ ).

The analysis of the simple effects for right-hemifield exposures also indicated an effect of the number of stimuli $[F(3,45)=37.14, p<0.001]$, but also a significant interaction of group $\times$ number $[F(6,45)=3.46, p<$ 0.01 ]. Analyses of this interaction revealed that the number of items presented had a significant effect on RTs in all three groups $\{[F(3,45)=11.3, p<0.001]$ for the normal controls, $[F(3,45)=6.0, p<0.005]$ for the nVAD group, $[F(3,45)=22.1, p<0.001]$ for the VAD group\}. Linear regressions applied to these data indicated, in the three groups, linear increases of RTs with increasing number of stimuli (controls: slope $=67.1 \mathrm{msec} / \mathrm{item}$, 


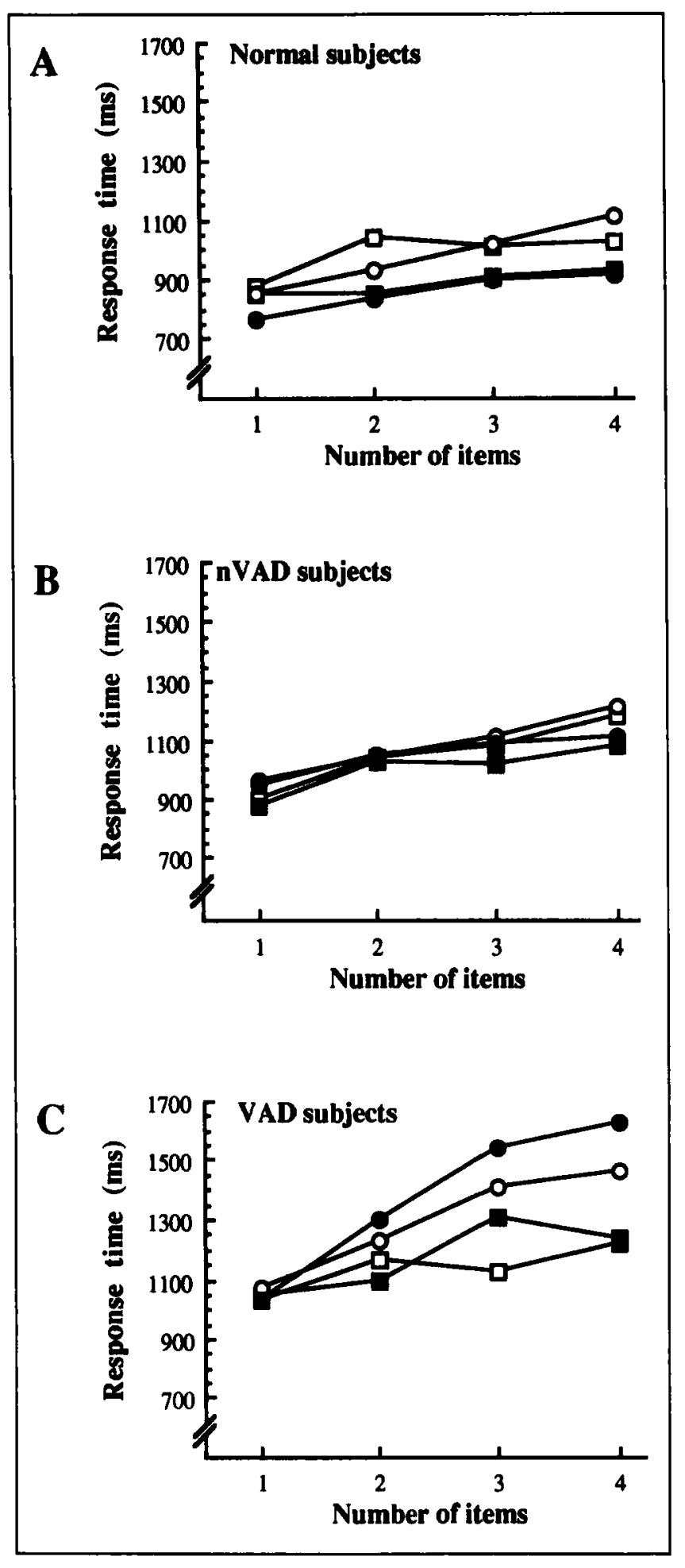

Figure 3. Mean RTs observed in Exp. 3 (conjunction search). (A) Control group. (B) nVAD group. (C) VAD group. Square, left hemifield display; circle, right-hemifield display; filled symbols, targetpresent trials; empty symbols, target-absent trials. Note that the scale of the vertical axis differs from that used in Figures 1 and 2.
Table 3. Percentages of Errors Observed in the Conjunction Search Experiment (Experiment 3$)^{a}$

\begin{tabular}{cccccc}
\hline $\begin{array}{c}\text { Number of } \\
\text { Items }\end{array}$ & Group & $L-A$ & $L-P$ & $R-A$ & $R-P$ \\
\hline & Control & & & & \\
1 & & 0.0 & 2.0 & 2.0 & 1.3 \\
2 & & 2.0 & 3.3 & 0.0 & 6.6 \\
3 & & 2.0 & 6.6 & 6.6 & 6.0 \\
4 & & 2.0 & 6.7 & 7.3 & 8.7 \\
& nVAD & & & & \\
1 & & 1.3 & 9.3 & 9.3 & 6.7 \\
2 & & 2.7 & 9.3 & 2.7 & 12.0 \\
3 & & 2.7 & 10.7 & 4.0 & 16.0 \\
4 & & 6.7 & 18.7 & 17.3 & 16.0 \\
& VAD & & & & \\
1 & & 6.7 & 4.4 & 8.9 & 2.2 \\
2 & & 8.9 & 2.2 & 8.9 & 4.4 \\
3 & & 6.7 & 0.0 & 11.1 & 5.5 \\
4 & & 8.9 & 15.5 & 8.9 & 15.5 \\
\hline
\end{tabular}

${ }^{a}$ Conventions are the same as in Table 1.

$r=1.0 ;$ nVAD: slope $=68.9 \mathrm{msec} / \mathrm{item}, r=0.99$; VAD: slope $=168.8 \mathrm{msec} / \mathrm{item}, r=0.98$ ). Separate analyses designed to compare the magnitude of the effect of the number of items with right-hemifield stimulation between the normal controls and each of the brain-damaged groups were conducted. These showed that while the effect of the number of items did not differ significantly between the control and nVAD groups (interaction of group $\times$ number: $F(3,39)<1$, subjects in the VAD group exhibited a larger increase of RTs with additional stimuli than the normal controls (interaction of group $x$ number: $F(3,39)=5.3, p<0.005)$.

\section{Discussion}

One first important aspect of the results observed during the search for a conjunction target is that there was a linear increase of RTs with the number of stimuli presented, as demonstrated by the linear regression analyses. This is consistent with the existing literature on conjunction search and indicates that the task was performed by the serial processing of the stimuli displayed.

A second point worth noting in the results of Exp. 3 is that the effect of number of items displayed on RTs did not vary significantly as a function of target presence or absence. This is at variance with most of the literature on conjunction search, which indicates slopes of RTs as 
a function of the number of items that are twice as large on target-absent trials as on target-present trials (Arguin \& Cavanagh, 1990; Dehaene, 1989; Quinlan \& Humphreys, 1987; Treisman, 1983, 1985, 1988; Treisman \& Gelade, 1980; Treisman et al., 1977). Such observations suggest a serial self-terminating search process (Snodgrass \& Townsend, 1980). In contrast, equal slopes on target-present and target-absent trials, as observed in Exp. 3, suggest a serial exhaustive search process (Snodgrass \& Townsend, 1980). In added support for this interpretation of the similar effect of the number of items when the target was present or absent, we performed an analysis of the standard deviations of the means of the data observed in each subject and each condition. Given a serial exhaustive process, the increase in the standard deviations with the number of items, if any, should not vary as a function of target presence since the process subjects have to go through is the same on target-present and target-absent trials. In contrast, given a serial selfterminating search process, standard deviations should increase more rapidly with the number of items on target-present trials than on target-absent trials. The reason for this is that whereas the total number of items examined remains constant for a given display size when the target is absent, this number becomes more and more variable as the display size increases on targetpresent trials. Congruent with a serial exhaustive search process in Exp. 3, the analysis applied on the standard deviations of RTs indicated no interaction between the effects of the number of stimuli and of the presence of the target $[F(3,45)=1.33$, n.s. $]$.

Exceptions to the general rule of a serial self-terminating process in the visual search for a conjunctive target have been reported previously (Arguin et al., 1990; Houck \& Hoffman, 1986; Pashler, 1987). It has been suggested by Houck and Hoffman (1986) that serial selfterminating search for a conjunction target is seen when eye movements may have occurred during the search process while serial exhaustive search is seen when eye movements are unlikely. The results of Exp. 3 are consistent with this hypothesis since they suggest a serial exhaustive search (similar slopes of RTs as a function of the number of items on target-present and target-absent trials) and the procedure eliminated all trials in which eye movements occurred.

The most important observation of Exp. 3 is that the VAD subjects demonstrated a much larger increase of RTs as a function of the number of items with righthemifield (contralesional) stimulation than the normal controls. In contrast, no difference between groups on the effect of the number of stimuli presented was observed with left-hemifield displays. These observations support the hypothesis that the integration of visual features, here orientation and color, requires attention. Thus, VAD patients, who have an attention deficit for contralesional stimulation, showed an impaired search rate with contralesional conjunction displays. More specifically, their search performance suggests an increase in the time required to process each individual conjunction stimulus presented in their contralesional visual field.

\section{GENERAL DISCUSSION}

The purpose of the present study was to assess the effect of an attention disorder on the perceptual processes involved in the encoding of visual features and in their integration. Previous research, notably by Treisman and collaborators, suggested that the encoding of visual attributes is a preattentive process performed by modules specialized for the analysis of specific visual dimensions. In contrast, the integration of visual features, necessary for the correct perception of their conjunctions, is a process that requires attention to be focused at the stimulus location. According to these hypotheses, a disorder of visual attention should result in defective feature integration, while leaving intact the processes that are responsible for the encoding of these features.

The experiments reported here support these hypotheses. Thus, with respect to the encoding of visual features, Exps. 1 and 2 demonstrated that brain-damaged subjects with an attention deficit performed similarly to normal controls in visual search tasks in which the target differed from distractors by a single feature, namely orientation and color. More specifically, these observations provided evidence for the capacity of patients with an attention disorder to encode these visual features in a spatially parallel manner. Such a dissociation between an attention disorder and the encoding of visual features is consistent with the notion of preattentive processing of orientation and color features.

In contrast, in Exp. 3, left brain-damaged subjects with an attention disorder exhibited a marked deficit with contralesional displays in a task requiring the search for a conjunction target. Specifically, they showed a much steeper increase of RTs with the number of items with contralesional displays than that seen in normal controls with the same stimulation.

Among the the alternative accounts that can be provided for the conjunction search deficit in the VAD group, some may readily be rejected. First, their impaired search rate for a conjunction target with contralesional stimulation may not be attributed to a nonspecific effect of brain damage since the nVAD group, who appeared to have intact attentional functions, did not show any impairment in this task relative to the control group. Moreover, the results of the VAD group cannot be accounted for by a deficit in encoding visual features. Thus, the results of Exps. 1 and 2, which involved the search for orientation and color targets, respectively, revealed no particular impairment in the VAD group and suggested a spatially parallel feature encoding in these subjects. 
Therefore, the results of Exp. 3 indicate the importance of attentional processes for feature integration. That is, the slowing of serial search for a conjunction target with contralesional displays in the VAD group appears to be specifically related to their attention deficit for contralesional stimulation.

These observations from Exp. 3 are inconsistent with the hypothesis of preattentive feature integration that has been proposed by a number of investigators who reported very shallow slopes of RTs with the number of items displayed during the search for particular conjunction targets (McLeod et al., 1988; Nakayama \& Silverman, 1986; Sagi, 1988). In fact, it appears that these rapid search rates for some features conjunctions may be accounted for while maintaining the hypothesis of attentional feature integration. Thus, Wolfe and his collaborators (Wolfe et al., 1989; see also Cave $\&$ Wolfe, 1990 and Wolfe, Stewart, Friedman-Hill, Yu, Shorter, \& Cave, 1990) as well as Treisman and Sato (1990) reported evidence indicating that preattentive processes that serve for feature encoding may contribute to rapidly direct attention to the target location-what they termed "parallel guidance." When such guidance is highly effective, this is assumed to lead to very shallow slopes in the search for a conjunction target since attention may be rapidly directed to its location. In this context, variations in the search rates between types of conjunction targets in normal individuals are explained, at least partially, by differences in the amount of noise that is present in the guidance signal coming from preattentive processes. That is, a decreased effectiveness of the guidance signal implies that more items need to be examined before the target can be found. Even with preattentive guidance, however, attention is assumed to be critical for feature integration in all cases, which is congruent with the results reported here.

What are the subcomponents of the conjunction search process that may be affected by the attention disorder of the VAD group and be responsible for their slowed search rates for a contralesional conjunction target? Three candidates may be considered. The first is an increase in the time necessary to integrate the features of a contralesional item once attention is focused at the location it occupies. The second is the time required to perform a spatial shift of attention from one stimulus to the next, which may be increased for contralesional stimulation in the VAD group. Third, it may be that the effectiveness of the preattentive guidance of the focus of spatial attention to the target location is decreased for contralesional stimuli in the VAD group. The observations reported here provide some clues with respect to this question and suggest that an increase in the time required for the feature integration process may be responsible for the impaired search rate of the VAD group for a conjunction target.

First, comparisons of the average slopes shown by the normal controls studied here in Exp. 3 and those re- ported by Wolfe et al. (1989) in a similar task suggest that preattentive guidance was not a factor in our experiment. In Exp. 3, the features used to make the stimuli were the colors red and green and the orientations horizontal and vertical and the average search rate shown by the normal controls was of about $51 \mathrm{msec} / \mathrm{item}$. In contrast, Wolfe et al. (1989), using the same features to construct their stimuli, observed much shallower slopes of RTs as a function of the number of items presented $(5.6 \mathrm{msec} / \mathrm{item}$ on target-present trials and $13.1 \mathrm{msec}$ item on target-absent trials). Of course, age (Plude \& Doussard-Roosevelt, 1989) may have been a factor in this large slope difference between the normal controls studied here and the subjects used by Wolfe et al. (1989). Still, under exposure conditions that were similar to those used in Exp. 3 and with identical stimuli, young normal subjects (mean age of 25 years) showed an average slope of about $25 \mathrm{msec} /$ item (Arguin et al., 1990), which is substantially larger than what was reported by Wolfe et al. (1989). One point that distinguishes Exp. 3 and the experiment reported by Arguin et al. (1990) from that of Wolfe et al. (1989) was the use of tachistoscopic displays in the former two, while exposure durations were unlimited in the latter. It therefore appears that preattentive guidance of the focus of attention, which can lead to very shallow slopes in the search for a conjunction target, may be functional only when the search items are visible. This possibility could account for the slope discrepancies between our own results and those of Arguin et al. (1990), which were observed under brief exposure conditions, and those reported by Wolfe et al. (1989) with unlimited viewing of the displays.

One aspect of the results of Exp. 2 (color search) also suggests that the rate at which VAD subjects are able to shift their spatial attention from one item to another in their (contralesional) right visual field is comparable to that of the normal controls. It should be recalled that in Exp. 2, serial search was observed in both the VAD and control groups on right-hemifield target-present trials. In addition, the slopes shown by these two groups did not differ significantly, suggesting that the speed of attention shifts from one item to the next did not differ. Given that the control and VAD groups did not differ on the speed of spatial attention shifts in Exp. 2, it appears unlikely that a difference on this process occurred in Exp. 3 (conjunction search).

To conclude, we have shown here that brain-damaged subjects with a disorder affecting the allocation of attention to the contralesional visual hemifield are markedly impaired in a task requiring the search for a conjunction target presented in that hemifield. By elimination, it appears that this deficit results from an increase in the time required for the feature integration process once attention has been focused at the location occupied by an item. In contrast to their deficit in feature integration, subjects with an attention disorder have been shown to perform the search for single features as effectively as 
neurologically intact individuals. These observations are congruent with the basic hypotheses of Treisman's feature integration theory, according to which feature encoding is preattentive while the integration of the separate features of an object requires attention.

\section{METHOD}

\section{Subjects}

Inclusion as well as exclusion criteria were applied for subject selection in order to control factors that otherwise might have rendered the results interpretation equivocal, and to make sure that subjects were able to perform the tasks adequately. Inclusion criteria were (1) right handedness, as assessed with the Edinburgh Handedness Inventory (score between +80 and +100 ; Oldfield, 1971) and (2) brain lesion of vascular origin, a first occurrence of brain damage, with a unique lesion lateralized to one hemisphere, as assessed by a CT scan examination (applies only to brain-damaged subjects). Exclusion criteria were (1) reduced and uncorrected visual acuity; this was assessed by asking the subject to read a few sentences printed in small type and presented at a distance of about $50 \mathrm{~cm}$; (2) ocular disease such as glaucoma or cataracts; the presence of either of these diseases was established either from the subject's self report or, in the case of patients, from their hospital charts; (3) color vision anomaly, as assessed by Ishihara's isochromatic plates (Ishihara, 1964); (4) visual field deficits, as assessed by campimetry (applies only to braindamaged subjects); (5) visual hemineglect, as assessed with the bells test (Gauthier, Dehaut, \& Joanette, 1989; applies only to brain-damaged subjects); extinction on double simultaneous stimulation was not assessed; (6) an aphasia that may impair the understanding of instructions (applies only to brain-damaged subjects). This was determined through consultation of the patients' hospital charts, who had all received a formal language investigation by a speech therapist.

Following the application of the selection criteria, eight left brain-damaged subjects ${ }^{2}$ whose mean age was 65 years were studied. The minimum time period between lesion onset and testing was of 2 months. Ten neurologically intact subjects whose mean age was 71 years served as controls.

All these subjects had previously been examined (Arguin et al., 1992) on a series of visuospatial cuing tasks (Eriksen \& Hoffman, 1973, 1974; Jonides, 1981; Müller \& Rabbitt, 1989; Posner, 1980; Posner, Walker, Friedrich, \& Rafal, 1984, 1987). Of the brain-damaged subjects, three (VAD group-visual attention deficit) showed results that differed from those of the normal controls. VAD subjects had longer RTs to contralesional than ipsilesional targets at short temporal intervals (50 and $150 \mathrm{msec}$ SOAs) following a spatial cue that indicated the hemifield in which the target would occur on $80 \%$ of the trials (valid cues).
This result occurred in the following cuing conditions: (1) with a central cue (arrowhead at fixation) that was valid or invalid, (2) with the peripheral onset of a square at an invalid location, and (3) with bilateral peripheral vertical gratings in which the spatial cue was the direction of motion of the bars in the gratings. Note that with these motion cues, no effect involving the effect of cue validity was found. The hemifield asymmetries observed in each of the conditions just mentioned were much reduced or absent at longer SOAs (600 and $1000 \mathrm{msec}$ ) between cues and targets.

This pattern of results indicates a deficit in allocating visual attention to contralesional stimulation in the VAD subjects. Specifically, the impairment appeared to affect the capacity of VAD subjects to maintain a high level of alertness for contralesional stimulation in the intervening period between trials. Thus, the presentation of a warning signal (the spatial cues-valid or invalid) served to progressively increase the level of alertness for contralesional stimulation in VAD subjects. At short SOAs ( 50 and $150 \mathrm{msec}$ ), the level of alertness in these patients was higher for ipsilesional than for contralesional stimulation but this asymmetry was no longer present at late SOAs (600 and $1000 \mathrm{msec}$ ). A similar deficit in maintaining alertness for contralesional stimulation during the time interval separating one trial from the next has previously been revealed in right brain-damaged patients through the use of a spatial cuing paradigm by Posner, Inhoff, Friedrich, and Cohen (1987). Previous work on alerting in neurologically intact subjects has shown that alerting does not affect the rate of information encoding in automatic pathways. Rather, it appears to affect the rate at which a higher level attention system reacts-not necessarily through a physical response- to the build-up of perceptual information in those automatic pathways (Posner \& Boies, 1971; Posner et al., 1987; Posner, Klein, Summers, \& Buggie, 1973; Thomas, 1974; see Posner, 1978 and Posner \& Peterson, 1990 for a detailed review of alerting).

In contrast to VAD subjects, the other brain-damaged subjects (nVAD group) showed performances in the visuospatial cuing tasks that were similar to those of the normal controls and which did not differ as a function of visual hemifield.

Figure 4 shows a reconstruction of the lesional sites observed in the nVAD subjects. The lesions suffered by the three VAD patients that have been tested in the visual search experiments reported in this paper are illustrated in Figure 5. Two other VAD patients who were examined on the spatial cuing experiments could not be tested in the visual search task since one showed a color vision deficit (deuteranopy) on the Ishihara plates and the other exhibited very important difficulties to perform a response choice through a button press (which was required for the visual search experiments) because of strong perseveration tendencies. The first of these patients suffered from a large cerebellar lesion while the 
Floure 4. Reconstruction of the lesional sites observed in the nVAD subjects from their CT scans. The gray areas represent lesional sites observed in only one subject, and black areas represent lesional sites seen in two subjects. Numbers identify the patient who showed the lesion illustrated closest to it.

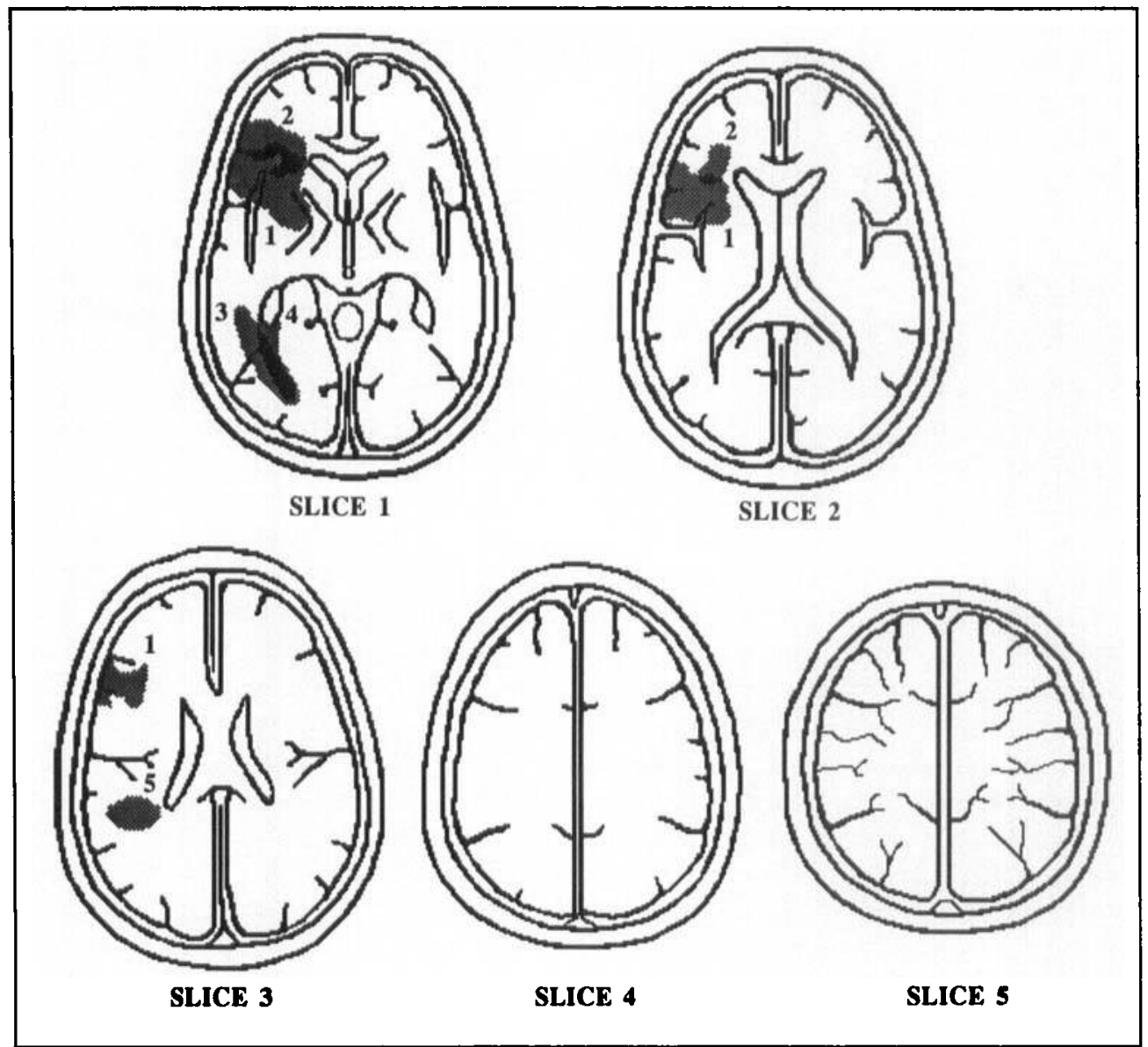

second had a lesion of the internal capsule. In spite of an apparent concentration of the brain damage shown in Figure 5 in the area of the parieto-occipitotemporal junction, it is not clear that the attention disorder of the $\mathrm{VAD}$ patients is specifically related to a lesion in this area. First, as indicated, two other VAD patients showed lesions that did not affect this region. Second, one of the nVAD patients (subject 5, Fig. 4) also showed a lesion in the parietotemporal area. The clearest difference between the brain damage showed by the VAD and nVAD subjects was the size of the lesions. Thus, the average volume of the lesions observed in the VAD patients was about four times larger than that seen in nVAD subjects.

Three VAD subjects were retested in the present experiments to determine the aspects of visual search that may be related to deficits of visual attention.

\section{Materials}

Experiments were controlled by an Amiga microcomputer and stimuli were displayed on an RGB monitor located at a distance of $57 \mathrm{~cm}$ from the subjects. Subjects rested their head on a chin rest. A two-button computer mouse was used for response production. The experiments were run in a dimly lit room.

An ocular fixation control was used to ensure that the stimuli were displayed to the proper visual field. This was achieved by the use of a pupil and corneal reflection tracking system (ISCAN, model RK-426) linked to the control computer. This tracking system analyzes video images obtained from a black and white camera equipped with an infrared filter. An infrared source served for illumination. Trials began only when the subject fixated his eyes on a central fixation point. If, during a trial, the subject shifted his ocular fixation toward the array of stimuli (displayed left or right of fixation) so that the distance between ocular fixation and the centermost stimulus was under $2.0^{\circ}$ of visual angle, that trial was immediately terminated and run again later in the session. Across experiments, an average of $1.7 \%$ of trials had to be eliminated this way.

\section{Stimull}

A white fixation stimulus (luminance of about $61 \mathrm{~cd} / \mathrm{m}^{2}$; CIE coordinates, $x=0.29, y=0.32$ ) was shown at the center of the display screen between trials. It was made of a $0.2^{\circ}$ dot surrounded by a $1.3^{\circ}$ empty circle. Subjects were instructed to keep their eyes directed toward the fixation location as much as possible throughout the experiment.

In Exp. 1, stimuli were white horizontal $\left(2.5^{\circ}\right.$ wide $X$ $0.4^{\circ}$ high $)$ and vertical $\left(0.5^{\circ}\right.$ wide $\times 2.4^{\circ}$ high $)$ bars. The 
Figure 5. Reconstruction of the lesional sites observed in the VAD subjects. Conventions are the same as in Figure 4.

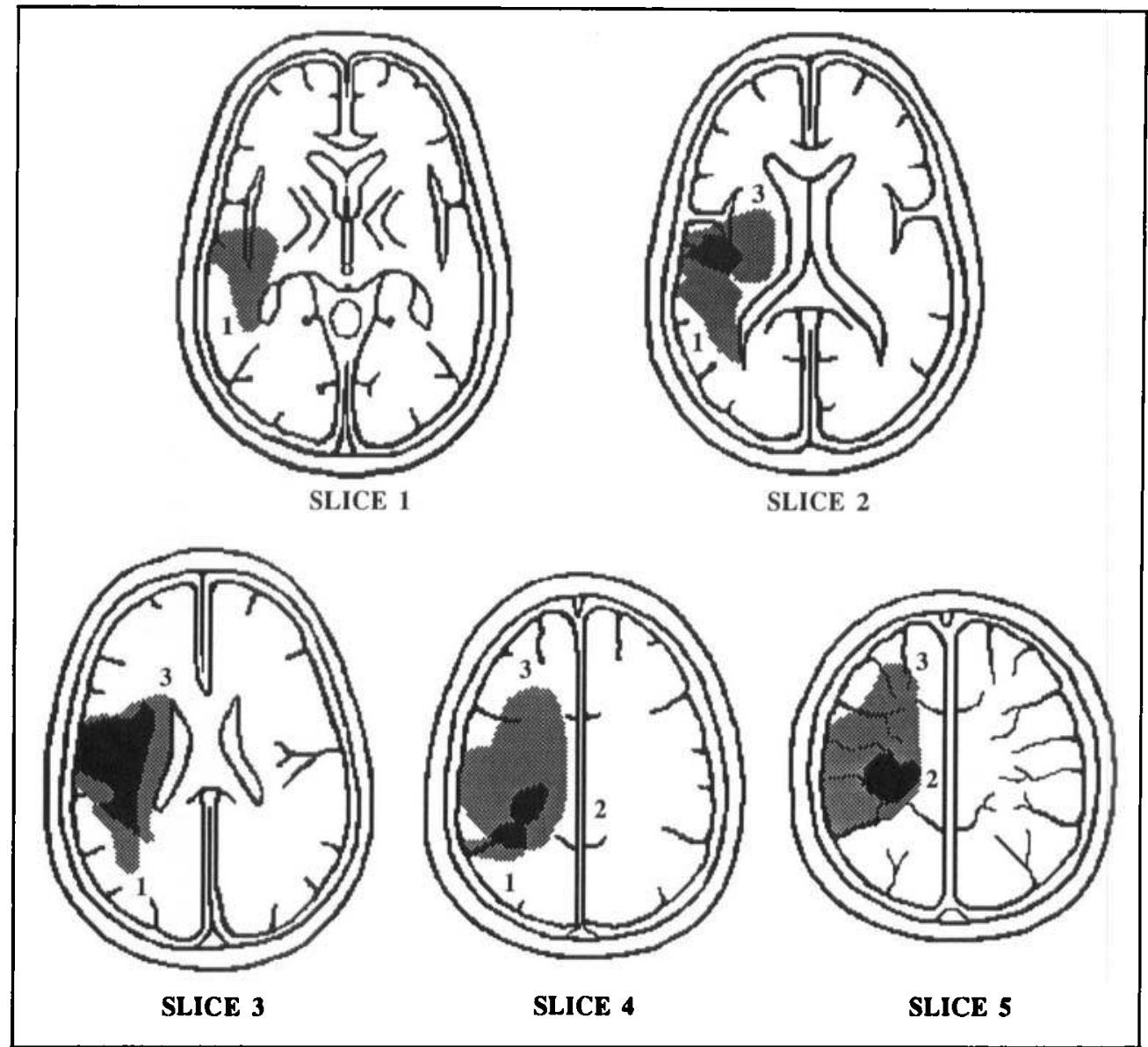

stimulus designated as the target was a horizontal bar and distractors were vertical bars.

In Exp. 2, stimuli were filled circles $\left(1.3^{\circ}\right.$ in diameter) that were either red (luminance of about $11 \mathrm{~cd} / \mathrm{m}^{2}$; CIE coordinates, $x=0.64, y=0.33$ ) or green (luminance of about $14 \mathrm{~cd} / \mathrm{m}^{2}$; CIE coordinates, $x=0.32, y=0.58$ ). Prior to the experiment, these colors were adjusted to equiluminance individually for each subject with the minimum flicker technique (Troscianko \& Low, 1985). The target the subjects had to report was a red circle and distractors were green circles.

In Exp. 3, stimuli were horizontal $\left(2.5^{\circ}\right.$ wide $\times 0.4^{\circ}$ high) and vertical $\left(0.5^{\circ}\right.$ wide $\times 2.4^{\circ}$ high $)$ bars that were either red or green. As in Exp. 2, these colors were adjusted to equiluminance for each subject individually with the minimum flicker technique prior to the experiment. The target stimulus was a red horizontal bar. One subgroup of distractors was made of red vertical bars and another of green horizontal bars. In displays comprising an even number of distractors, half of them were red vertical and half were green horizontal. In other cases, the display contained one more distractor (selected randomly) from one subgroup than from the other. Thus, in Exp. 3, the target the subjects had to report differed from distractors by a unique conjunction of orientation and color.

In each experiment, stimulus duration was established individually for each subject during the 35 practice trials that immediately preceded the experimental session. This was done according to the following procedure. During the five first practice trials, stimulus duration was fixed at $400 \mathrm{msec}$. From the sixth practice trial, each trial on which the subject gave a correct response was followed by a reduction in exposure duration. Inversely, each trial on which the subject made an error was followed by an increase in display duration. Initially, the value by which stimulus duration was either increased or decreased was set at $134 \mathrm{msec}$. Afterward, each time a correct response was followed by an error and each time an error was followed by a correct response, this value was halved. The minimum and maximum possible exposure durations were 150 and $600 \mathrm{msec}$, respectively. This procedure rapidly established an exposure duration that remained quite stable during the last few practice trials and that yielded an adequate level of accuracy. The exposure duration in the experimental session was that used on the last practice trial. Table 4 shows the mean display durations used in each group in Exps. 1, 2, and 3.

Stimuli were always displayed unilaterally (either to the left or right of the fixation point). Each item in an array was located randomly within an eight-location grid that was organized in two columns and four rows. The distance separating the center of each of these locations 
Table 4. Mean Exposure Durations in Experiments 1, 2, and 3

\begin{tabular}{lccc}
\hline & \multicolumn{3}{c}{ Experiment } \\
\cline { 2 - 4 } Group & $\begin{array}{c}1 \\
(\mathrm{msec})\end{array}$ & $\begin{array}{c}2 \\
(\mathrm{msec})\end{array}$ & $\begin{array}{c}3 \\
(\mathrm{msec})\end{array}$ \\
\hline Control & 195 & 180 & 237 \\
nVAD & 163 & 157 & 374 \\
VAD & 239 & 156 & 261 \\
\hline
\end{tabular}

was $3.9^{\circ}$ horizontally and $3.6^{\circ}$ vertically. To break the regularity of the display, each item was shifted between $\pm 0.35^{\circ}$ along the horizontal and $\pm 0.28^{\circ}$ along the vertical relative to the center of its assigned location in the matrix. The direction and size of this shift were determined randomly. The minimum distance between the centermost stimulus and the fixation location was $5.6^{\circ}$.

\section{Procedure}

The order in which the experiments were conducted was the same for all subjects (Exp. 1 first and Exp. 3 last). The three experiments required subjects to respond on each trial whether a prespecified target was present in the display. Subjects were instructed to respond as rapidly as possible while avoiding errors. All subjects used their left hand to respond since half the brain-damaged subjects suffered from a right-arm plegia or paresis. To indicate that the target was present, subjects pressed the right button on a two-button computer mouse with their index finger and pressed the left button with their middle finger to indicate that it was absent. All responses were immediately followed by an auditory feedback emitted by the control computer. Correct responses emitted between 150 and $3000 \mathrm{msec}$ after the onset of the stimuli were immediately followed by a high-pitch sound and errors were followed by a low-pitch sound. Responses given less than $150 \mathrm{msec}$ or more than $3000 \mathrm{msec}$ after the onset of stimulation were also followed by a lowpitch sound. These latter trials were eliminated from data analyses and run again later in the experimental session. Across experiments, an average of $0.002 \%$ of trials were eliminated for RTs under $150 \mathrm{msec}$ and an average of $0.22 \%$ of trials were eliminated for RTs above $3000 \mathrm{msec}$.

The number of stimuli displayed on a single trial was one, two, three, or four. The selection of these values was determined by two separate constraints: (1) A sufficient number of levels of the set size factor was required to obtain meaningful estimates of its effect on RTs. (2) The maximum number of items that could be presented had to be sufficiently low that accuracy remained high even in the more difficult task of conjunction search (Exp. 3). The target was present on half the trials and absent in the other half.
The effects of four factors were examined. Those were the subject group (control, nVAD, and VAD), the hemifield to which the stimuli were presented (left or right), target presence (present vs. absent), and the number of stimuli $(1,2,3$, or 4$)$. Conditions were distributed randomly within a 240-trial experimental session, with the constraint that there were 15 trials per condition. This experimental session was immediately preceded by 35 practice trials. The main dependent variable was RT.

\section{Acknowledgments}

The research reported here was conducted for partial fulfillment of the first author's Ph.D. degree and was led at the Laboratoire Théophile-Alajouanine, Centre Hospitalier Côtedes-Neiges, and at the Département de psychologie, Université de Montréal. Financial support was provided by a graduate scholarship from the Conseil de Recherches Médicales du Can. ada (CRMC) to Martin Arguin, by Grant PG-28 from the CRMC to Yves Joanette, and by Grant A8606 from the National Science and Engineering Research Council of Canada to Patrick Cavanagh. Yves Joanette is Scientist of the CRMC. The order of the second and third authors was established on the basis of a previous coin toss.

\section{Notes}

1. We thank an anonymous reviewer for pointing this out. 2. Six right brain-damaged subjects were also examined. However, only one of them could be assessed satisfactorily since the others tended to fall asleep after a few minutes into the experiment. This is probably related to the vigilance problems that are frequently associated with right-brain lesions (De Renzi \& Faglioni, 1965; Heilman, 1985) and the right-hemisphere superiority of normal individuals in vigilance tasks (Heilman \& Van Den Abell, 1979, 1980). The facts that subjects were tested in a dimly lit room and that the search tasks involved no verbal interactions with the experimenter may also have contributed to the difficulty experienced in testing right brain-damaged patients. The subject who could be tested performed similarly to the left brain-damaged individuals who did not show evidence for an attention deficit. Since he is the only subject with a right brain lesion in our sample, his results will not be reported.

Reprint requests should be sent to Martin Arguin, Ph.D., Département de psychologie, Université de Montréal, C.P. 6128, Succursale A, Montréal, Québec, Canada H3C 3J7.

\section{REFERENCES}

Allman, J. M., Baker, J. F., Newsome, W. T., \& Peterson, S. E. (1981). Visual topography and function: Cortical areas in the owl monkey. In C. N. Woolsey (Ed.), Cortical sensory organization, Vol. 2: Multiple visual areas (pp. 17-185). Clifton, NJ: Humana Press.

Arguin, M., \& Cavanagh, P. (1988). Parallel processing of two disjunctive targets. Perception and Psychophysics, 44, 22-30. Arguin, M., \& Cavanagh, P. (1990). The feature integration process is serial and exhaustive. Canadian Psychology, 31, 206. 
Arguin, M., Cavanagh, P., \& Joanette, Y. (1993). A lateralized alerting deficit in left brain-damaged patients. Psychobiology, in press.

Arguin, M., Joanette, Y., \& Cavanagh, P. (1990). Comparing the cerebral hemispheres on the speed of spatial shifts of visual attention: Evidence from serial search. Neuropsychologia, 28, 733-736.

Bergen, J. R., \& Julesz, B. (1983). Parallel versus serial processing in rapid pattern discrimination. Nature (London), 303, 696.

Briand, K. A., \& Klein, R. M. (1987). Is Posner's "beam" the same as Treisman's "glue"?: On the relation between visual orienting and feature integration theory. Journal of Experimental Psychology: Human Perception and Performance. 13, 228-241.

Bryden, M. P. (1982). Laterality: Functional asymmetry in the intact brain. New York: Academic Press.

Cavanagh, P. (1988). Pathways in early vision. In Z. Pylyshyn (Ed.), Computational processes in buman vision: An interdisciplinary perspective (pp. 245-289). Norwood, NJ: Ablex.

Cavanagh, P., Arguin, M., \& Treisman, A. (1990). Effect of stimulus domain on visual search for orientation and size features. Journal of Experimental Psychology: Human Perception and Performance, 16, 479-491.

Cave, K. R., \& Wolfe, J. M. (1990). Modeling the role of parallel processing in visual search. Cognitive Psychologv. $22,225-271$.

Davidoff, J. (1982). Studies with non-verbal stimuli. In J. G. Beaumont (Ed.), Divided visual field studies of cerebral organization. New York: Academic Press.

Dehaene, S. (1989). Discriminability and dimensionality effects in visual search for featural conjunctions: A functional pop-out. Perception and Psychophysics, 46, 72-80.

De Renzi, E., \& Faglioni, P. (1965). The comparative efficiency of intelligence and vigilance tests in detecting hemispheric change. Cortex, 1, 410-433.

De Yoe, E. A, \& Van Essen, D. C. (1988). Concurrent processing streams in monkey visual cortex. Trends in Neuroscience, 11, 219-226.

Dick, M., Ullman, S., \& Sagi, D. (1987). Parallel and serial processes in motion detection. Science, 237, 400-402.

Duncan, J., \& Humphreys, G. (1989). A resemblance theory of visual search. Psycbological Review, 96, 433-458.

D'Zmura, M. (1991). Color in visual search. Vision Research, 31, 951-966.

Egeth, H. E., Virzi, R. A., \& Garbart, H. (1984). Searching for conjunctively defined targets. Joumal of Experimental Psy. chology: Human Perception and Performance, 10, 32-39.

Eglin, M. (1987). The effects of different attentional loads on feature integration in the cerebral hemispheres. Perception and Psychophysics, 42, 81-86.

Eglin, M., Robertson, L. C., \& Knight, R. T. (1989). Visual search performance in the neglect syndrome. Journal of Cognitive Neuroscience, 1, 372-385.

Eriksen, C. W., \& Hoffman, J. E. (1973). The extent of processing of noise elements during selective coding from visual displays. Perception and Psychopbysics, 14, 155-160.

Eriksen, C. W., \& Hoffman, J. E. (1974). Selective attention: Noise suppression or signal enhancement? Bulletin of the Psychonomic Society, 4, 587-589.

Estes, W. K. (1972). Interactions of signal and background variables in visual processing. Perception and Psychopbysics, 12, 278-286.

Farmer, E. W., \& Taylor, R. M. (1980). Visual search through color displays: Effects of target-background similarity and background uniformity. Perception and Psychopbysics, 27, 267-272.

Gauthier, L., Dehaut, F., \& Joanette, Y. (1989). The bells test: A quantitative and qualitative test for visual neglect. International Journal of Clinical Neuropsychology, 11, 49-54.

Gordon, I. E. (1968). Interactions between items in visual search. Journal of Experimental Psycbology, 76, 348-355.

Gordon, I. E., Dulewicz, V., \& Winwood, M. (1971). Irrelevant item variety and visual search. Journal of Experimental Psychology, 88, 295-296.

Heilman, K. M. (1985). Neglect and related disorders. In K. M Heilman \& E. Valenstein (Eds.), Clinical neuropsychology (2nd Ed., pp. 243-293). New York: Oxford University Press.

Heilman, K. M., \& Van Den Abell, T. (1979). Right hemispheric dominance for mediating cerebral activation. Neuropsychologia, 17, 315-321.

Heilman, K. M., \& Van Den Abell, T. (1980). Right hemisphere dominance for attention: The mechanism underlying hemispheric asymmetry of inattention. Neurology, 30, 327-330.

Houck, M. R, \& Hoffman, J. E. (1986). Conjunction of color and form without attention: Evidence from an orientationcontingent color aftereffect. Joumal of Experimental Psychology: Human Perception and Performance, 12, 186199.

Ishihara, S. (1964). Tests for color blindness. Tokyo: Kanehara Shuppan.

Jonides, J. (1981). Voluntary versus automatic control over the mind's eye's movement. In J. Long \& A. Baddeley (Eds.), Attention and performance $I X$ (pp. 187-203). Hillsdale, NJ: Erlbaum.

Kaas, J. H. (1989). Why does the brain have so many visual areas? Journal of Cognitive Neuroscience, 1, 121-135.

Keele, S. W., Cohen, A., Ivry, R., Liotti, M., \& Yee, P. (1988). Tests of a temporal theory of attentional binding. Journal of Experimental Psycbology: Human Perception and Per. formance, 14, 444-452.

Kinsbourne, M. (1970). A model for the mechanism of unilateral neglect. Transactions of the American Neurological Association, 95, 143-146.

McIntyre, C., Fox, R., \& Neale, J. (1970). Effects of noise similarity and redundancy on the information processed from brief visual displays. Perception and Psychophysics, 7, 328332.

McLeod, P., Driver, J., \& Crisp, J. (1988). Visual search for a conjunction of movement and form is parallel. Nature (London), 332, 154-155.

Mesulam, M. M. (1981). A cortical network for directed attention and unilateral neglect. Annals of Neurology 10, 309325.

Moraglia, G., Maloney, K. P., Fekete, E. M., \& Al-Basi, K. (1989). Visual search along the colour dimension. Canadian Journal of Psychology; 43, 1-12.

Morrow, L. A, \& Ratcliff, G. (1988). The disengagement of covert attention and the neglect syndrome. Psycbobiology, $16,261-269$.

Müller, H. J., \& Rabbitt, P. M. A (1989). Reflexive and voluntary orienting of visual attention: Time course of activation and resistance to interruption. Journal of Experimental Psycbology: Human Perception and Performance, 15, 315330.

Nakayama, K., \& Silverman, G. H. (1986). Serial and parallel processing of visual feature conjunctions. Nature (London), 320, 264-265.

Oldfield, O. D. (1971). The assessment and analysis of handedness: The Edinburgh Inventory. Neurobsvchologia. 9.97113.

Pashler, H. (1987). Detecting conjunctions of color and form: Reassessing the serial search hypothesis. Perception and Psychophysics, 41, 191-201.

Plude, D. J., \& Doussard-Roosevelt, J. A. (1989). Aging, selec- 
tive attention, and feature integration. Psychology and Aging 4, 98-105.

Posner, M. I. (1978). Cbronometric explorations of mind. Hillsdale, NJ: Erlbaum.

Posner, M. I. (1980). Orienting of attention. Quarterly Journal of Experimental Psychology, 32, 3-25.

Posner, M. I., \& Boies, S. J. (1971). Components of visual attention. Psychological Review, 78, 391-408.

Posner, M. I., Inhoff, A W., Friedrich, F. J., \& Cohen, A (1987). Isolating attentional systems: A cognitive-anatomical analysis. Psychobiology, 15, 107-121.

Posner, M. I., Klein, R., Summers, J., \& Buggie, S. J. (1973). On the selection of signals. Memory and Cognition, 1, 2-12.

Posner, M. 1., \& Peterson, S. E. (1990). The attention system of the human brain. Annual Review of Neuroscience, 13, 2542.

Posner, M. I., Walker, J. A, Friedrich, F. J., \& Rafal, R D. (1984). Effects of parietal injury on covert orienting. Journal of Neurascience, 4, 1863-1874.

Posner, M. I., Walker, J. A, Friedrich, F. J., \& Rafal, R. D. (1987). How do the parietal lobes direct covert attention? Neuropsycbologia, 25, 135-145.

Prinzmetal, W. (1981). Principles of feature integration in visual perception. Perception and Psychopbysics, 30, 330-340.

Prinzmetal, W., Presti, D. E., \& Posner, M. I. (1986). Does attention affect visual feature integration? Joumal of Experimental Psychology: Human Perception and Performance, 12, 361-369.

Quinlan, P. T., \& Humphreys, G. W. (1987). Visual search for targets defined by combinations of color, shape, and size: An examination of the task constraints on feature and conjunction searches. Perception and Psychophysics, 41, 455472.

Riddoch, M. J., \& Humphreys, G. W. (1987). Perceptual and action systems in unilateral visual neglect. In M. Jeannerod (Ed.), Neurophysiological and neunopsychological aspects of spatial neglect (pp. 151-181). New York: North-Holland.

Roy, E. A, Reuter-Lorenz, P., Roy, L. G., Copland, S., \& Moscovitch, M. (1987). Unilateral attention deficits and hemispheric asymmetries in the control of attention. In $\mathrm{M}$. Jeannerod (Ed.), Neuropbysiological and neuropsychological aspects of spatial neglect (pp. 25-39). New York: NorthHolland.

Sagi, D. (1988). The combination of spatial frequency and orientation is effortlessly perceived. Perception and Psychophysics, 43, 601-603.

Sagi, D., \& Julesz, B. (1985). "Where" and "what" in vision. Science, 228, 1217-1219.

Snodgrass, J. G., \& Townsend, J. T. (1980). Comparing parallel and serial models: Theory and implementation. Joumal of Experimental Psychology: Human Perception and Performance, 6, 330-354.

Steinman, S. B. (1987). Serial and parallel search in pattern vision. Percetion, 16, 389-399.

Thomas, E. (1974). The selectivity of preparation. Psycbological Review, 81, 443-464.

Treisman, A (1982). Perceptual grouping and attention in visual search for features and for objects. Journal of Experi- mental Psychology: Human Perception and Performance, 8, 194-214.

Treisman, A (1983). The role of attention in object perception. In O. J. Braddick \& A C. Sleigh (Eds.), Physical and biological processing of images (pp. 316-325). New York: Springer-Verlag.

Treisman, A (1985). Preattentive processing in vision. Computer Vision, Grapbics, and Image Processing, 31, 156-177.

Treisman, A. (1988). Features and objects. Quarterly Journal of Experimental Psychology, 40A, 201-237.

Treisman, A. (1991). Search, similarity, and integration of features between and within dimensions. Journal of Experimental Psychology: Human Perception and Performance, $17,652-676$.

Treisman, A, \& Gelade, G. (1980). A feature-integration theory of attention. Cognitive Psychology, 12, 97-136.

Treisman, A, \& Gormican, S. (1988). Feature analysis in early vision: Evidence from search asymmetries. Psychological Review, 95, 15-48.

Treisman, A, \& Paterson, R. (1984). Emergent features, attention, and object perception. Journal of Experimental Psy. chology: Human Perception and Performance, 10, 12-31

Treisman, A, \& Sato, S. (1990). Conjunction search revisited. Ioumal of Exterimental Psucholory: Human Percetion and Performance, 16, 459-478.

Treisman, A, \& Schmidt, H. (1982). Illusory conjunctions in the perception of objects. Connitive Psycholoen. 14. 107141 .

Treisman, A, \& Souther, J. (1985). Search asymmetry: A diagnostic for preattentive processing of separable features. Joumal of Experimental Psychology: General, 114, 285310.

Treisman, A., Sykes, M., \& Gelade, G. (1977). Selective attention and stimulus integration. In S. Dornic (Ed.), Attention and performance VI (pp. 333-361). Hillsdale, NJ: Erlbaum.

Troscianko, T., \& Low, I. (1985). A technique for presenting isoluminant stimuli using a microcomputer. Spatial Vision, 1, 197-202.

Virzi, R. A., \& Egeth, H. E. (1984). Is meaning implicated in illusory conjunctions? Journal of Experimental Psychology: Human Perception and Performance, 10, 573-580.

Wolfe, J. M., Cave, K. R., \& Franzel, S. L. (1989). Guided search: An alternative to the feature integration model for visual search. Joumal of Experimental Psychology: Human Perception and Performance, 15, 419-433.

Wolfe, J. M., Friedman-Hill, S. R., Stewart, M. I., \& O'Connell, K. M. (1992). The role of categorization in visual search for orientation. Journal of Experimental Psychology: Human Perception and Performance, 18, 34-49.

Wolfe, J. M., Stewart, M. I., Friedman-Hill, S. R., Yu, K. P., Shorter, A D., \& Cave, K. R. (1990). Limitations on the parallel guidance of visual search: Color $\times$ Color and Orientation $\times$ Orientation conjunctions. Journal of Experimental Psycbology: Human Percetion and Performance, 16, 879892.

Zeki, S. M. (1978). Functional specialization in the visual cortex of the rhesus monkey. Nature (London). 274.423-438. 


\section{This article has been cited by:}

1. Andrea Tales, Gillian Porter. 2008. Visual attention-related processing in Alzheimer's disease. Reviews in Clinical Gerontology 18:03, 229. [CrossRef]

2. Manon W. Jones, Holly P. Branigan, M. Louise Kelly. 2008. Visual deficits in developmental dyslexia: relationships between non-linguistic visual tasks and their contribution to components of reading. Dyslexia 14:2, 95-115. [CrossRef]

3. Andrea Peru, Leonardo Chelazzi. 2008. Local (focussed) and global (distributed) visual processing in hemispatial neglect. Experimental Brain Research 187:3, 447-457. [CrossRef]

4. Josephine C. H. Li, Geoff P. Sampson, Trichur R. Vidyasagar. 2007. Interactions between luminance and colour channels in visual search and their relationship to parallel neural channels in vision. Experimental Brain Research 176:3, 510-518. [CrossRef]

5. LEON Y. DEOUELL, YARON SACHER, NACHUM SOROKER. 2005. Assessment of spatial attention after brain damage with a dynamic reaction time test. Journal of the International Neuropsychological Society 11:06. . [CrossRef]

6. Jeffrey Schatz, Suzanne Craft, Myles Koby, Michael R. DeBaun. 2004. Asymmetries in Visual-Spatial Processing Following Childhood Stroke. Neuropsychology 18:2, 340-352. [CrossRef]

7. Ute Leonards, Julie Palix, Christoph Michel, Vicente Ibanez. 2003. Comparison of Early Cortical Networks in Efficient and Inefficient Visual Search: An Event-Related Potential StudyComparison of Early Cortical Networks in Efficient and Inefficient Visual Search: An Event-Related Potential Study. Journal of Cognitive Neuroscience 15:7, 1039-1051. [Abstract] [PDF] [PDF Plus]

8. Philip T. Quinlan. 2003. Visual feature integration theory: Past, present, and future. Psychological Bulletin 129:5, 643-673. [CrossRef]

9. Marina Pavlovskaya, Haim Ring, Zeev Groswasser, Shaul Hochstein . 2002. Searching with Unilateral NeglectSearching with Unilateral Neglect. Journal of Cognitive Neuroscience 14:5, 745-756. [Abstract] [PDF] [PDF Plus]

10. Raja Parasuraman, Pamela M. Greenwood, Trey Sunderland. 2002. The apolipoprotein E gene, attention, and brain function. Neuropsychology 16:2, 254-274. [CrossRef]

11. Ute Leonards, Stefan Sunaert, Paul Van Hecke, Guy A. Orban . 2000. Attention Mechanisms in Visual Search-An fMRI StudyAttention Mechanisms in Visual Search-An fMRI Study. Journal of Cognitive Neuroscience 12:supplement 2, 61-75. [Abstract] [PDF] [PDF Plus]

12. Jo Iles, Vincent Walsh, Alex Richardson. 2000. Visual search performance in dyslexia. Dyslexia 6:3, 163-177. [CrossRef]

13. Ramesh S. Bhatt, Carolyn Rovee-Collier. 1996. Infants' Forgetting of Correlated Attributes and Object Recognition. Cbild Development 67:1, 172. [CrossRef] 